\title{
Possible mechanisms for a marine benthic regime shift in the North Sea
}

\author{
Egbert H. van Nes ${ }^{1, *}$, Teresa Amaro' ${ }^{2}$, Marten Scheffer ${ }^{1}$, Gerard C. A. Duineveld ${ }^{2}$ \\ ${ }^{1}$ Department of Aquatic Ecology and Water Quality Management, Wageningen University, PO Box 8080, \\ 6700 DD Wageningen, The Netherlands \\ ${ }^{2}$ Royal Netherlands Institute for Sea Research, PO Box 59, 1790 AB Den Burg, The Netherlands
}

\begin{abstract}
A sharp regime shift from a brittle star Amphiura filiformis dominated state to a burrowing mud shrimp Callianassa subterranea dominated situation was observed in a region of the North Sea known as the Frisian Front in the mid-1990s. No indications exist that food levels or other relevant conditions in this part of the North Sea had changed significantly. However, the new state has persisted until the present. This could suggest that this regime shift represents a transition between alternative stable community states. We propose a potential explanation for the existence of 2 stable states, which agrees with experimental and field observations. We demonstrated experimentally that sediments inhabited by burrowing shrimps are more susceptible to sediment resuspension by tidal currents and wave forces than sediments inhabited by brittle stars. Although the burrowing shrimps apparently thrive under these conditions, successful recruitment of brittle stars may be hampered on such unstable frequently resuspended sediments. This implies a positive feedback; brittle stars promote sediment stability, which favors their persistence. We created a model to demonstrate that this feedback between the benthic community and sediment stability may cause both the shrimp dominated state and the brittle star dominated state to be stable under the same external conditions.
\end{abstract}

KEY WORDS: Regime shift · Amphiura filiformis - Callianassa subterranea - Catastrophic shift · Alternative stable state $\cdot$ Bioturbation $\cdot$ Resuspension $\cdot$ Competition

\section{INTRODUCTION}

Sharp shifts in population dominance to a contrasting state have been observed in marine communities at scales varying from individual kelp beds (Steneck et al. 2002) and coral reefs (Done 1991, Knowlton 1992, Nystrom et al. 2000) to the entire North Sea (Beaugrand 2004, Weijerman et al. 2005) and even the Pacific Ocean (Hare \& Mantua 2000). In several of these cases, no abrupt change was observed in the external conditions that could explain the sharp character of the regime shift. Recent insights show that regime shifts in ecosystems can occur without strong external forcing if the system has alternative states (Scheffer et al. 2001, Collie et al. 2004, Scheffer \& van Nes 2004). Due to positive feedback mechanisms, some ecosystems may have 2 or more stable states under the same external conditions (Fig. 1). Catastrophic transitions to the contrasting state may occur in such systems even if environmental conditions change only gradually or if there is a short-term external disturbance. If resilience (sensu Holling 1973) is low, i.e. if the system is close to a threshold point $\left(F_{1}\right.$ or $F_{2}$ in Fig. 1), a small external disturbance may be enough to trigger a catastrophic shift. Once such a regime shift has occurred, the original state may be hard to restore, as the resilience of a new stable state may be large.

We analyzed a benthic shift in the southern part of the Frisian Front, a section of the North Sea positioned on the Dutch Continental Shelf at the transition between the permanently mixed waters of the South- 

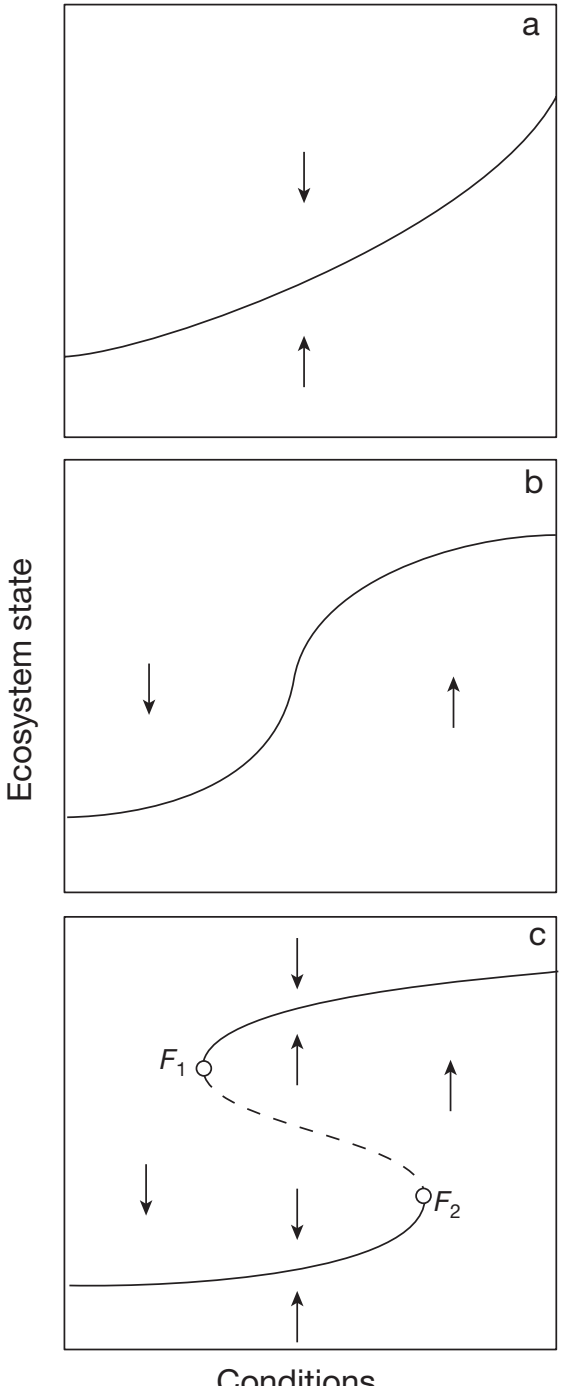

Fig. 1. Possible ways in which the equilibrium of ecosystems may react to changed conditions. If the response of the ecosystem is (a) gradual, or (b) sigmoidal, there is only one equilibrium for each condition. However, in some cases the equilibrium curve may have an S-shape (c). In such cases, there is a zone with 3 equilibria for a given condition. As indicated by the arrows, the middle equilibrium is repelling and is, thus, unstable. The 2 bending points $F_{1}$ and $F_{2}$ are called 'bifurcation points' as the model behaviour changes at these points. Modified from Scheffer et al. (2000)

ern Bight (25 m depth) and the summer-stratified water masses of the Oyster Grounds (50 m depth) (Creutzberg 1983). Due to the local deposition of particulate matter and fresh phytodetritus, this area is characterized by high densities and high biomass of interfacefeeding species with a well-defined north-south zonation (Creutzberg et al. 1984). Moreover, during a large part of the year the water column over the enriched zone is characterized by elevated chlorophyll a concentrations (Creutzberg 1985, Cramer 1991). The brit- tle star Amphiura filiformis used to be extremely dominant and stable in this area. In the period between 1984 and 1992, its densities ranged from 1433 to 1750 ind. $\mathrm{m}^{-2}$ (Duineveld \& van Noort 1986). However, in the years after 1992 the population collapsed to less than $10 \%$ of its original densities (Fig. 2a). Associated with this sharp shift, the entire macrobenthic fauna community changed and the burrowing mud shrimp Callianassa subterranea became a dominant species (Amaro 2005) (Fig. 2b). The timing of the shifts does not coincide with the regime shifts that were observed in the entire North Sea (Beaugrand 2004, Weijerman et al. 2005).

In this article, we proposed a positive feedback mechanism in the competition between the 2 dominant species. We used a simple model to indicate whether this positive feedback could imply that the system has 2 alternative states with dominance of either species. The model could not show what the actual trigger of the regime shift was. However, it did indicate that the observed shift could plausibly be a regime shift between 2 stable states.

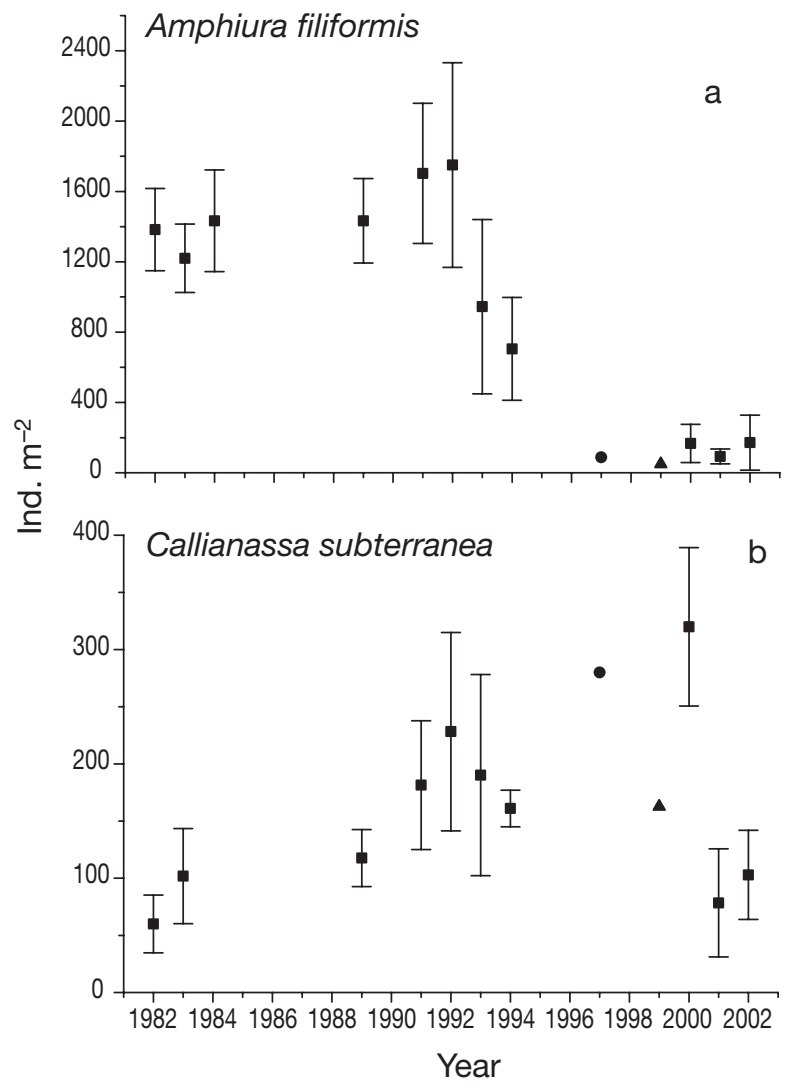

Fig. 2. Average densities of (a) Amphiura filiformis and (b) Callianassa subterranea at the standard monitoring station $\left(4^{\circ} 30^{\prime} \mathrm{N}\right.$ and $53^{\circ} 70^{\prime} \mathrm{N}$ ) from 1982 to 2002 (after 2000 data for C. subterranea are not reliable). $\mathbf{\square}: 4$ individual boxcores $\left(\right.$ area $=0.07 \mathrm{~m}^{2}$ each); $0: 1$ big boxcore $\left(\text { area }=0.25 \mathrm{~m}^{2}\right)_{\text {; }}$ $\Delta: 4$ boxcores together $\left(\right.$ area $\left.=0.272 \mathrm{~m}^{2}\right)$. Error bars $\pm \mathrm{SD}$ 


\section{MATERIALS AND METHODS}

The model. Field measurements reveal high concentrations of suspended sediments in the Frisian Front region. This indicates that sediment erosion and resuspension are important features of the current ecosystem state. Amaro (2005) demonstrated experimentally that Amphiura filiformis reduces the susceptibility of sediments to erosion by water movement, whereas Callianassa subterranea makes sediments more susceptible to resuspension. This implies that a shift from $A$. filiformis to $C$. subterranea may effectively promote sediment erosion. At the same time, A. filiformis and C. subterranea (or other mud shrimps like Upogebia deltaura) are likely to compete for the same food source (Amaro 2005). These 2 mechanisms could imply a positive feedback loop as the mud shrimps apparently thrive under conditions with high resuspension, and successful recruitment of its competitor (A. filiformis) seems less likely on such unstable, frequently resuspended sediments. Thus, as soon as C. subterranea becomes dominant, they create conditions that reduce the chances for their competitors, thus improving their own conditions. In contrast, dominance of $A$. filiformis could prevent sediment resuspension and, therefore, this species also improves its own conditions.

To explore whether the mechanisms described can cause alternative equilibria, we formulated a simple competition model of the brittle stars Amphiura filiformis $(A)$ and burrowing mud shrimps Callianassa subterranea $(C)$ based on the models of Armstrong \& McGehee (1980). We assumed that both species are competing for one resource $F$ (e.g. space or food). The limitation of the growth rate of both species $\left(r_{A}\right.$ and $r_{C}$ ) is described by a Monod function (with halfsaturation coefficients $H_{F, A}$ and $H_{F, C}$ ). Both species have a fixed loss factor $\left(m_{A}\right.$ and $\left.m_{C}\right)$. The resource is not renewable and both species use or occupy a fixed fraction $\left(a_{A}\right.$ or $\left.a_{C}\right)$ of the total available resource $\left(F_{0}\right)$. The basic model is described as follows:

$$
\begin{aligned}
& \frac{\mathrm{d} A}{\mathrm{~d} t}=r_{A} A \frac{F}{F+H_{F, A}}-m_{A} A \\
& \frac{\mathrm{d} C}{\mathrm{~d} t}=r_{C} C \frac{F}{F+H_{F, C}}-m_{C} C \\
& F=F_{0}-a_{A} A-a_{C} C \quad(F \geq 0)
\end{aligned}
$$

To this basic competition model, we added the effect that both species have on the erosion threshold of the sediment $(R)$. These effects were shown experimentally by Amaro (2005). Amphiura filiformis has a stabilizing effect on the sediment stability, whereas the burrowing activities of Callianassa subterranea make the sediment more susceptible to erosion, which is described as:

$$
R=R_{0}+R_{A} \frac{A}{h_{A}+A}+R_{C} \frac{C}{h_{C}+C}
$$

where $R_{0}$ represents the erosion threshold of the sediment, and the second and third terms represent the effects of Amphiura filiformis and C. subterranea on the sediment erosion threshold, respectively $\left(R_{C}\right.$ is a negative value). Both species have a maximum effect $\left(R_{A}\right.$ or $\left.R_{C}\right)$ and the relation between the biomass and the erosion threshold is modeled with a Monod function $\left(h_{A}\right.$ and $\left.h_{C}\right)$. The increased susceptibility of the sediment to erosion means that there is more resuspension if the water movement $(w)$ exceeds the threshold $R$. Amaro (2005) showed that the relation between resuspension and water movement is a sigmoidal function (Fig. 3). There are indications that this increased resuspension can result in reduced reproductive success of $A$. filiformis (Woodin et al. 1998, Marinelli \& Woodin 2002). We modeled this as a slight increase in the mortality of A. filiformis. It seems unlikely that $C$. subterranea is harmed significantly as this species normally creates highly dynamical sediments (Witbaard \& Duineveld 1989, Rowden \& Jones 1994). The competition model thus becomes:

$$
\begin{aligned}
& \frac{\mathrm{d} A}{\mathrm{~d} t}=r_{A} A \frac{F}{F+H_{F, A}}-m_{A} A-m_{\text {resusp }}(R, W) A \\
& \frac{\mathrm{d} C}{\mathrm{~d} t}=r_{B} C \frac{F}{F+H_{F, C}}-m_{C} C \\
& m_{\text {resusp }}(R, W)=m_{E} \frac{W^{p}}{W^{p}+R^{p}}
\end{aligned}
$$

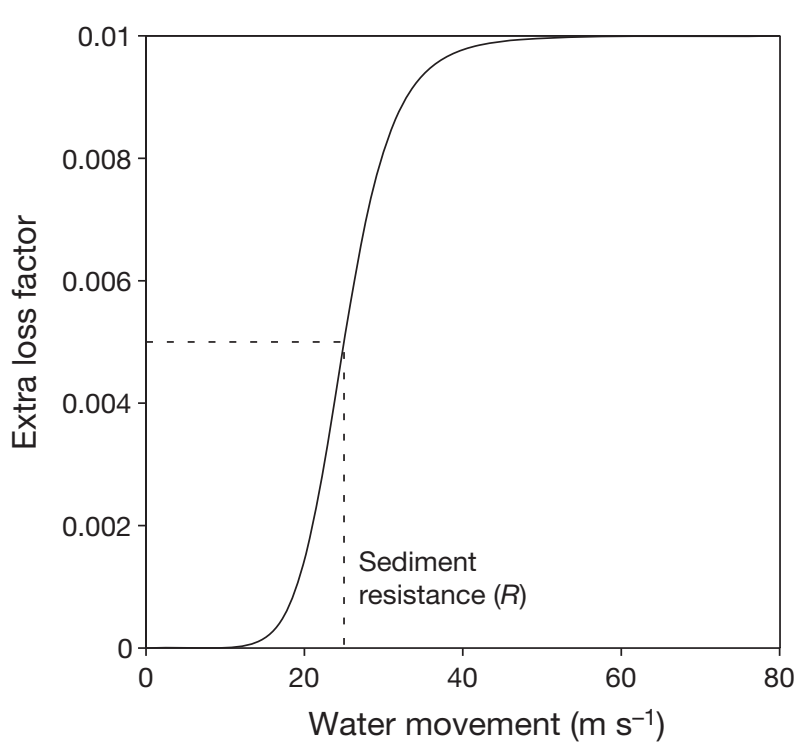

Fig. 3. Resuspension of sediment is dependent on the sediment erosion threshold $(R)$ and the water movement $(w)$. Above this threshold, sediment is resuspended, which results in a slightly increased mortality of Amphiura filiformis 
The interpretation and dimensions of variables and parameters as well as the default values used are summarized in Table 1. The values relative to the erosion threshold and wind effect were estimated from the results of laboratory experiments and field samples, whereas growth rates were taken from the literature (Muus 1981, Rowden \& Jones 1994, Josefson et al. 1995).

In Eq. (3), water movement is a fixed parameter. As this is not realistic, we also generated a noisy water movement for some analyses. We used the recurrent relation of Hasselmann (1976) on a daily basis to generate red noise (i.e. a signal with autocorrelation) with an approximate period of $\lambda$ days (red noise when $\lambda>1$ ):

$$
w_{(t)}=\left(1-\frac{1}{\lambda}\right)\left(w_{(t-1)}-\bar{W}\right)+\bar{W}+\beta \varepsilon
$$

in which $\varepsilon$ is the number drawn from a standard normal distribution, $\beta$ is determining the amount of noise and $\overline{\mathrm{w}}$ is the average water movement. The simulations were done using a 4th order Runga-Kutta procedure as implemented in MATLAB. The 2-dimensional bifurcation plots were created with bifurcation analyzing software (LOCBIF, Khibnik et al. 1992).

\section{RESULTS}

The simple competition model without sediment effect (Eq. 1) cannot have alternative stable states. Appendix 1 shows this model can only have 1 stable equilibrium and 2 unstable trivial equilibria. In all of these equilibria, the biomass of at least 1 species is zero. Only if there is a 4 th equilibrium in which the biomass of both species is larger than zero, can there be coexistence of both species or alternative stable states. In the latter case, the 4 th equilibrium is unstable. In the simple competition model, the species that is able to grow with lower resource levels or that has a lower mortality rate is superior (Appendix 1). This agrees with the competitive exclusion principle (Hardin 1960), which predicts that the maximum number of coexisting species equals the number of resources (Armstrong \& McGehee 1980). We assume that Amphiura filiformis is superior to Callianassa subterranea with respect to resource competition, as there are situations where A. filiformis is the dominant species.

Both species are ecological engineers (Jones et al. 1994) as they change the susceptibility of sediment to resuspension (Amaro 2005). If we assume that Amphiura filiformis is negatively affected by increased suspended solids, the model indeed can have 2 alternative stable states for realistic parameter values (corresponding to our experimental data). This can be understood graphically as the suspended solids effect causes the equilibrium line (nullcline) of $A$. filiformis to bend down at higher biomasses of Callianassa subterranea (Fig. 4a), making it possible for both nullclines to cross and the 4 th equilibrium to exist (Fig. 4b). The model can now have 2 stable states with dominance of either A. filiformis or C. subterranea. Between both stable nodes, an unstable equilibrium exists called a saddle point. This equilibrium is part of the separatrix, a line that represents all combinations of $A$. filiformis

Table 1. Default parameters of the model. References: (1) calibrated to get realistic biomass values of both species; (2) Amphiura filiformis is assumed more efficient than Callianassa subterranea; (3) based on experiments of Amaro (2005); (4) reasonable value; (5) assumption; (6) Muus (1981), Josefson et al. (1995); (7) Rowden \& Jones (1994); (8) dependent on wind, arbitrary default value. *Arbitrary resource units

\begin{tabular}{|c|c|c|c|c|}
\hline Parameter & Description & Default value & Unit & Reference \\
\hline$a_{A}$ & Resource occupation by A. filiformis & 0.15 & - & (1) \\
\hline$a_{C}$ & Resource occupation by C. subterranea & 0.05 & - & (1) \\
\hline$F_{0}$ & Total available resources & 1 & * & (1) \\
\hline$h_{A}$ & Effect of $A$. filiformis on resistance of sediment & 2.5 & $\mathrm{~g} \mathrm{~m}^{-2}$ & (3) \\
\hline$H_{F, A}$ & Half-saturation coefficient of resource for A. filiformis & 0.5 & * & $(2)$ \\
\hline$H_{F, C}$ & Half-saturation coefficient of resource for C. subterranea & 1 & * & $(2)$ \\
\hline$h_{C}$ & Effect of C. subterranea on resistance of sediment & 5 & $\mathrm{~g} \mathrm{~m}^{-2}$ & (3) \\
\hline$m_{A}$ & Mortality rate of $A$. filiformis & 0.01 & $\mathrm{~d}^{-1}$ & (4) \\
\hline$m_{E}$ & Extra mortality of $A$. filiformis due to resuspension & 0.01 & $\mathrm{~d}^{-1}$ & $(4)$ \\
\hline$m_{C}$ & Mortality rate of $C$. subterranea & 0.01 & $d^{-1}$ & (4) \\
\hline$p$ & Power of a Hill function & 8 & - & (5) \\
\hline$R_{0}$ & Resistance of sediment for resuspension & 0.25 & $\mathrm{~m} \mathrm{~s}^{-1}$ & (3) \\
\hline$r_{A}$ & Growth rate of $A$. filiformis & 0.04 & $\mathrm{~d}^{-1}$ & (6) \\
\hline$R_{A}$ & Maximum effect of $A$. filiformis on resuspension & 0.05 & $\mathrm{~m} \mathrm{~s}^{-1}$ & (3) \\
\hline$r_{C}$ & Growth rate of C. subterranea & 0.04 & $\mathrm{~d}^{-1}$ & $(7)$ \\
\hline$R_{C}$ & Maximum effect of C. subterranea on resuspension & -0.05 & $\mathrm{~m} \mathrm{~s}^{-1}$ & (3) \\
\hline$w$ & Water movement & 0.25 & $\mathrm{~m} \mathrm{~s}^{-1}$ & (8) \\
\hline
\end{tabular}




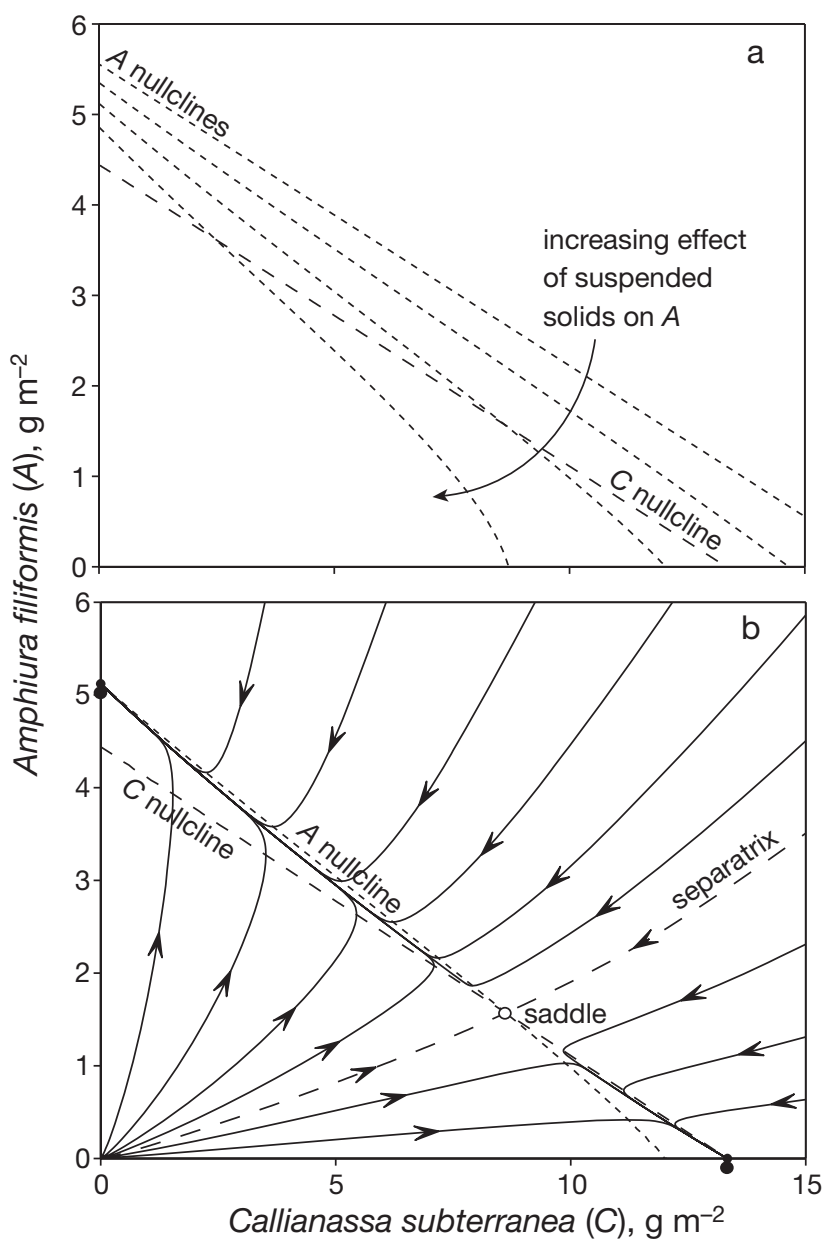

Fig. 4. (a) The negative effect of suspended solids caused by the burrowing activity of Callianassa subterranea on Amphiura filiformis makes the nullcline of the latter bend down. This way it is possible for both nullclines to intersect as both lines are no longer parallel. The system then has alternative stable states; (b) The phase plane with some trajectories at a moderate water movement $(w=25)$. There are 2 alternative equilibria (dominance of either species). For parameter definitions and values see Table 1

and C. subterranea when it is uncertain which species could become dominant. In other words, it represents the border in the state space between the basins of attraction of both equilibria. Simulations that start at one side of the separatrix will always go to the same equilibrium.

To check the robustness of this result, we analyzed the effect of different parameters on the result. The existence of alternative equilibria is highly dependent on the water movement (Fig. 5). At a water movement of 0.22 and $0.29 \mathrm{~m} \mathrm{~s}^{-1}$ there are 2 thresholds called transcritical bifurcations ( $T_{1}$ and $T_{2}$ in Fig. 5). Between both thresholds, 2 alternative stable states exist. A simulation of the behaviour of the system in response to stochastic fluctuations in the water movement demon- strates that this bistability in a strongly fluctuating environment could lead to incidental regime shifts such as the one observed at the Frisian Front (Fig. 6). Water movement crossing the 'bifurcation value' briefly is insufficient to cause a shift. Only after the water movement is above the critical value for longer periods, can a regime shift occur. There are also long periods in which both species can coexist in a variable environment.

We also checked the effects of some other parameters on the range of water movements where alterna-

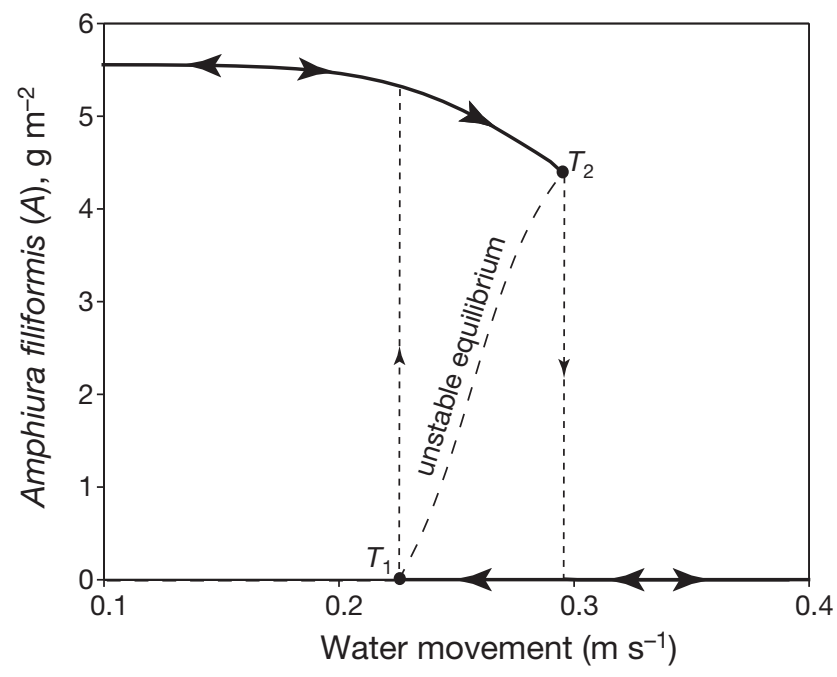

Fig. 5. One-dimensional bifurcation diagram of the effect of water movement $(w)$. Between both transcritical bifurcations $\left(T_{1}\right.$ and $T_{2}$ ) there are alternative equilibria

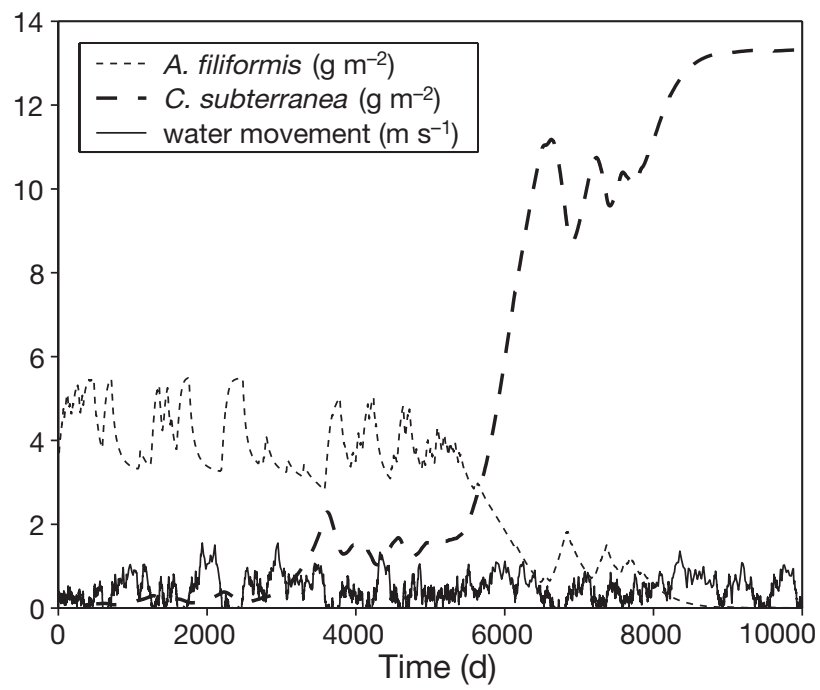

Fig. 6. Simulation of the effect of noise on water movement on the shift to the other state. Mean water movement $\bar{w}$ was $0.45 \mathrm{~m} \mathrm{~s}^{-1}$. Though this value is well above the transcritical bifurcation $\left(T_{2}\right)$, the variations can postpone the regime shift for a long period $\left(\beta=0.05 \mathrm{~m} \mathrm{~s}^{-1}, \lambda=80 \mathrm{~d}, w_{(t)}\right.$ was forced to positive values) 
tive equilibria occur. The extra loss of Amphiura filiformis due to erosion $\left(m_{E}\right)$ is an important parameter as it determines how strong the A. filiformis nullcline is bent down. There is a certain minimum effect needed to bend the nullcline strongly enough (ca. $0.005 \mathrm{~d}^{-1}$ ). Above this value the zone of alternative equilibria increases rapidly, and further increase of the parameter has little effect (Fig. 7a). The parameter $m_{A}$ (loss of A. filiformis) must be between 0.016 and $0.005 \mathrm{~d}^{-1}$ for alternative equilibria (Fig. $7 b$ ). From the equations in Appendix 1, one can deduce that if $m_{A}$ increases $0.016 \mathrm{~d}^{-1}, A$. filiformis is simply the inferior competitor, so Callianassa subterranea will always become dominant. In contrast, if $A$. filiformis becomes a very strong competitor (mortality loss $<0.005 \mathrm{~d}^{-1}$ ), the effect of increased resuspension is never strong enough to allow A. filiformis to disappear. Similarly, the halfsaturation coefficient of resource for resource limitation of $A$. filiformis $\left(H_{F, A}\right)$ needs to be between 2 boundaries (Fig. $7 \mathrm{c}$ ). If $H_{F, A}$ exceeds $1, A$. filiformis is not superior, or if $H_{F, A}$ is below ca. 0.4, the sediment effect is not strong enough.

Finally, it should be noted that in a qualitative sense shrimps are not essential to allow the model to produce alternative stable states. As Amphiura filiformis stabilizes the sediment, it promotes its own favorable conditions. Therefore, even without suppressing Callianassa subterranea the stabilizing of the sediment is a positive feedback. However, simulations show that the measured effect of brittle stars on sediment stability $\left(R_{C}\right)$ and the assumed extra mortality due to suspended matter $\left(m_{E}\right)$ are both not strong enough to let alternative stable states arise (results not shown).

\section{DISCUSSION}

Shifts between alternative states are usually induced by some disturbance, but the likelihood of such a shift depends also on the resilience of a state, i.e. the disturbance an ecosystem can take and still return to the same state (Holling 1973). Importantly, the observation of a sudden shift in a community is not necessarily related to alternative stable states (Scheffer \& Carpenter 2003). Two obvious alternative explanations would be: (1) there has been a permanent shift in an important controlling factor (e.g. temperature), or (2) the system has been hit by a severe disturbance from which it is simply slow to recover. Let us first consider these 2 possible options to the alternative stable state explanation.

With respect to the first option, we have no evidence that external control factors such as food resources of the North Sea or the state of the North Atlantic oscillation are systematically different in the new state from

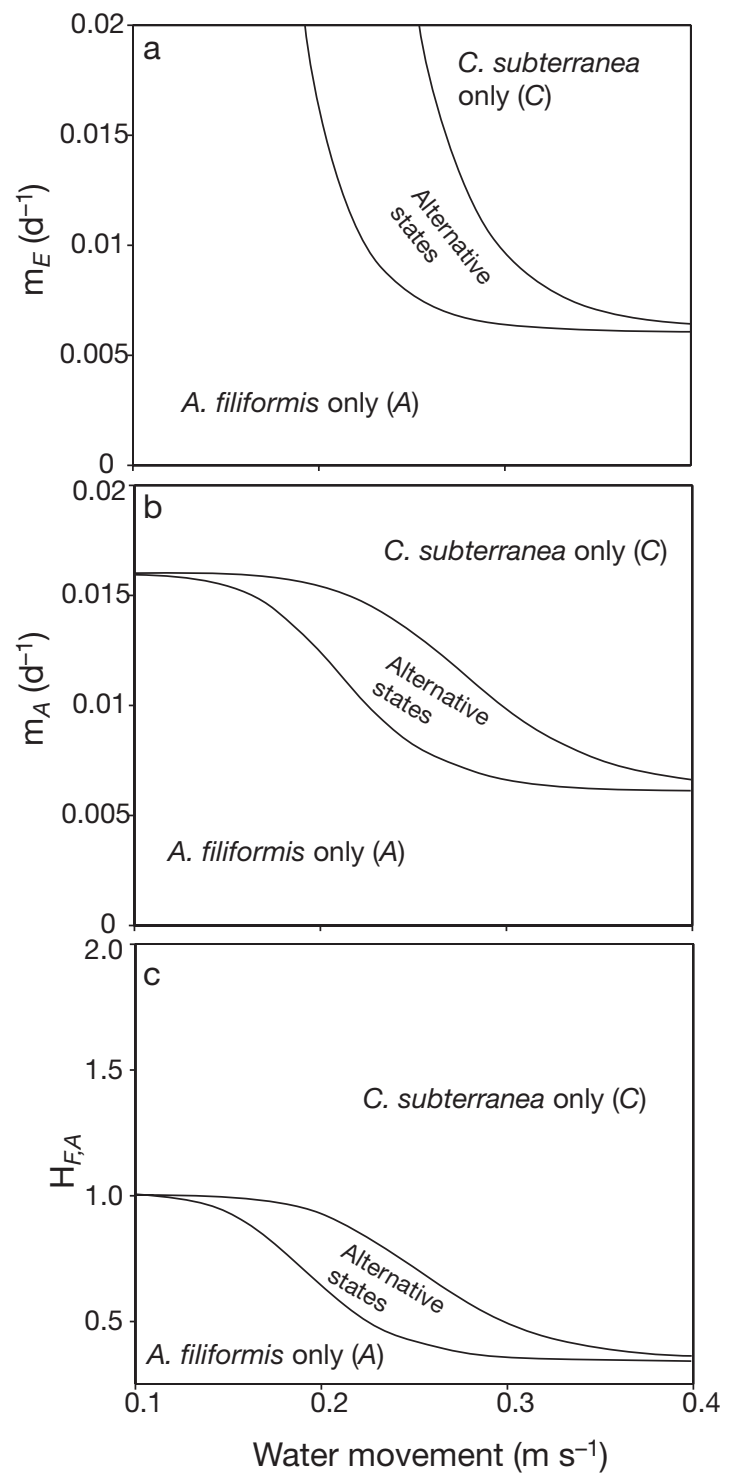

Fig. 7. Two-dimensional bifurcation diagrams of (a) extra loss due to erosion $\left(m_{E}\right)$ vs. water movement $(w)$; and (b) loss of $A$. filiformis $\left(m_{A}\right)$ vs. water movement $(W)_{\text {; }}$ and $(c)$ half-saturation coefficient of resource for Amphiura filiformis $\left(H_{F, A}\right)$ vs. water movement $(w)$. The bifurcation plots were created using LOCBIF (Khibnik et al. 1992). All other parameters were at the baseline level (Table 1)

what was observed during the brittle star state. Amaro et al. (2003) tried to link the decline in densities of Amphiura filiformis to a food shortage by analyzing variations in the shell growth of the filter feeder bivalve Mya truncata from the Frisian Front during the period of interest. The authors concluded that there was no direct coupling between fluctuations in density of $A$. filiformis and variations in growth of $M$. truncata. It, therefore, seemed unlikely that a change in food conditions would have caused the dramatic collapse of A. filiformis. 
The second alternative explanation would be that the system has been slow in recovering from a disturbance such as trawling activity or an extreme shear stress due to storm and tidal current action. However, in view of the generation time and growth rates of these Amphiura filiformis, the $5 \mathrm{yr}$ since the regime shift should have provided sufficient time for the brittle star populations to recover. The persistence of the new community state, therefore, suggests that a stabilizing mechanism exists to maintain a Callianassa subterranea dominated situation and prevent $A$. filiformis from recovering to its original densities.

Our model suggests that the interaction between sediment stability and the benthic community is a plausible mechanism that could cause alternative stable states in this system. Although our observations of suspended solids in the field and the measured differential effect of the 2 key species on sediment stability agree with the model, we obviously do not have proof that the proposed mechanism is indeed responsible for the apparent stability of the 2 contrasting states.

In fact, we did not consider many potentially important aspects of the biology of the species, partly because these factors are poorly known. For instance, age structure dynamics may have been important, and synchronous die-off of the adult brittle star population combined with long-term lack of recruitment could have caused the rapid decline in abundance. Indeed, for 10 yr juveniles have been scarce, particularly in the southernmost areas of the Frisian Front (Amaro 2005). Moreover, we have no data on the negative effect of sediment erosion on the brittle stars, even though it seems quite reasonable to assume that sediment resuspension may prevent the larvae from settling. Changes in sediment surface chemistry caused by disturbance of sediments, may affect larval settlement (Woodin et al. 1998, Marinelli \& Woodin 2002). Given the high numbers of Amphiura filiformis in the Frisian Front in the late 1990s, negative impacts of enhanced erodability on larval settlement do not seem to be very relevant. Another uncertainty is the nature of the resource competition between shrimps and brittle stars. Stable isotope analyses suggest that on our site they have essentially the same diet. However, A. filiformis is a passive suspension feeder (Buchanan \& Moore 1986, Loo et al. 1996, Solan \& Kennedy 2002), whereas Callianassa subterranea is a subsurface deposit feeder (Stamhuis et al. 1996, Stamhuis et al. 1998). This would suggest that the brittle stars have 'primacy' in the food competition as they trap the food particles before they settle and become available to the shrimps. In contrast, other aspects of the interaction between the species could contribute to bistability. For instance, shrimps could cause juvenile mortality of the brittle star recruits (Rhoads \& Young 1970). Direct competition for space could be another important aspect in the interaction between both species (Wilson 1990).

Although we have stressed the effects of the competition between Callianassa subterranea and Amphiura filiformis, the species C. subterranea is not essential to obtain the bistability in the model. Our analysis showed that a simpler mechanism, i.e. only the positive feedback between brittle stars and sediment stability, might potentially lead to alternative stable states. This mechanism would be analogous to the positive feedback between sediment stability and benthic microbial communities that cause alternative stable states on tidal flats (Van de Koppel et al. 2001) and lake sediments (Scheffer et al. 2003). However, simulations showed that the measured effect of brittle stars on sediment stability was not strong enough to obtain alternative stable states.

What event actually triggered the regime shift remains unresolved. One possibility is an episode of intense local trawl fishery. This could tip the balance, as fragile species such as Amphiura filiformis live within the penetration depth of a beam trawl. In contrast, fluctuations in water movement, temperature or food availability also may have had an impact. Our simulations illustrate that the system with alternative attractors can show a striking regime shift in response to a randomly fluctuating environment, even if no obvious trigger such as an anomaly in the environmental fluctuations appears to be present (Fig. 6). This illustrates just how elusive the search for causes of regime shifts can be if one focuses merely on the analysis of field patterns.

Acknowledgements. This study was supported by a grant awarded by Fundação Para a Ciência e Tecnologia and Fundo Social Europeu to Teresa Amaro.

\section{LITERATURE CITED}

Amaro T (2005) The benthic shift of the Frisian Front (Southern North Sea) ecosystem-possible mechanisms. PhD thesis, Wageningen University

Amaro T, Duineveld G, Bergman M, Witbaard R (2003) Growth variations in the bivalve Mya truncata: a tool to trace changes in the Frisian Front macrofauna (southern North Sea)? Helgol Mar Res 57:132-138

Armstrong RA, McGehee R (1980) Competitive exclusion. Am Nat 115:151-169

Beaugrand G (2004) The North Sea regime shift: evidence, causes, mechanisms and consequences. Prog Oceanogr 60:245-262

Buchanan JB, Moore JJ (1986) A broad review of variability and persistence in the Northumberland benthic fauna1971-85. J Mar Biol Assoc UK 66:641-657

Collie JS, Richardson K, Steele JH (2004) Regime shifts: can ecological theory illuminate the mechanisms? Prog Oceanogr 60:281-302

Cramer A (1991) Benthic metabolic activity at frontal systems in the North Sea. PhD thesis, University of Amsterdam 
Creutzberg F (1983) Biological activity in an area with a tidally-induced front. ICES CM 1983/L:1-13

Creutzberg F (1985) A persistent chlorophyll a maximum coinciding with an enriched benthic zone. In: Gibbs PE (ed) Proc 19th Eur Mar Biol Symp. Cambridge University Press, Cambridge, p 97-108

Creutzberg F, Wapenaar P, Duineveld G, Lopez NL (1984) Distribution and density of the benthic fauna in the southern North Sea in relation to bottom characteristics and hydrographic conditions. Rapp PV Reun Cons Int Explor Mer 183:101-110

Done TJ (1991) Phase shifts in coral reef communities and their ecological significance. Hydrobiologia 247:121-132

Duineveld GCA, van Noort GJ (1986) Observations on the population dynamics of Amphiura filiformis (Ophiuroidea: Echinodermata) in the southern North Sea and its exploitation by the dab Limanda limanda. Neth J Sea Res 20: 85-94

Hardin G (1960) The competitive exclusion principle. Science 131:1292-1297

Hare SR, Mantua NJ (2000) Empirical evidence for North Pacific regime shifts in 1977 and 1989. Prog Oceanogr 47: 103-145

Hasselmann K (1976) Stochastic climate models, Part I: theory. Tellus 28:473-485

Holling CS (1973) Resilience and stability of ecological systems. Annu Rev Ecol Syst 4:1-23

Jones CG, Lawton JH, Shachak M (1994) Organisms as ecosystem engineers. Oikos 69:373-386

Josefson AB, Jensen JN, Nielsen TG, Rasmussen B (1995) Parameters of a benthic suspension feeder along a depth gradient across the pycnocline in the southern Kattegat, Denmark. Mar Ecol Prog Ser 125:107-115

Khibnik AI, Kuznetsov YA, Levitin VV, Nikolaev EV (1992) Continuation techniques and interactive software for bifurcation analysis of ODE's and iterative maps. Physica D 62:360-370

Knowlton N (1992) Thresholds and multiple stable states in coral reef community dynamics. Am Zool 32:674-682

Loo LO, Jonsson PR, Sköld M, Karlsson Ö (1996) Passive suspension feeding in Amphiura filiformis (Echinodermata: Ophiuroidea): feeding behaviour in flume flow and potential feeding rate of field populations. Mar Ecol Prog Ser 139:143-155

Marinelli RL, Woodin SA (2002) Experimental evidence for linkages between infaunal recruitment, disturbance, and sediment surface chemistry. Limnol Oceanogr 47:221-229

Muus K (1981) Density and growth of juvenile Amphiura filiformis (Ophiuroidea) in the Oresund. Ophelia 20:153-168

Nystrom M, Folke C, Moberg F (2000) Coral reef disturbance and resilience in a human-dominated environment. Trends Ecol Evol 15:413-417

Rhoads DC, Young DK (1970) Influence of deposit-feeding organisms on sediment stability and community trophic structure. J Mar Res 28:150-178

Rowden AA, Jones MB (1994) A contribution to the biology of the burrowing mud shrimp, Callianassa subterranea (Decapoda, Thalassinidea). J Mar Biol Assoc UK 74: 623-635

Scheffer M, Carpenter SR (2003) Catastrophic regime shifts in ecosystems: linking theory to observation. Trends Ecol Evol 18:648-656

Scheffer M, van Nes EH (2004) Mechanisms for marine regime shifts: can we use lakes as microcosms for oceans? Prog Oceanogr 60:303-319

Scheffer M, Carpenter SR, Foley JA, Folke C, Walker B (2001) Catastrophic shifts in ecosystems. Nature 413:591-596

Scheffer M, Portielje R, Zambrano L (2003) Fish facilitate wave erosion. Limnol Oceanogr 48:1920-1926

Solan M, Kennedy R (2002) Observation and quantification of in situ animal-sediment relations using time-lapse sediment profile imagery (t-SPI). Mar Ecol Prog Ser 228: 179-191

Stamhuis EJ, Reede-Dekker T, van Etten Y, de Wiljes JJ, Videler JJ (1996) Behaviour and time allocation of the burrowing shrimp Callianassa subterranea (Decapoda, Thalassinidea). J Exp Mar Bio Ecol 204:225-239

Stamhuis EJ, Dauwe B, Videler JJ (1998) How to bite the dust: morphology, motion pattern and function of the feeding appendages of the deposit-feeding thalassinid shrimp Callianassa subterranea. Mar Biol 132:43-58

Steneck RS, Graham MH, Bourque BJ, Corbett D, Erlandson JM, Estes JA, Tegner MJ (2002) Kelp forest ecosystems: biodiversity, stability, resilience and future. Environ Conserv 29:436-459

Van de Koppel J, Herman PMJ, Thoolen P, Heip CHR (2001) Do multiple stable states occur in natural ecosystems? Evidence from tidal flats. Ecology 82:3449-3461

Weijerman M, Lindeboom H, Zuur AF (2005) Regime shifts in marine ecosystems of the North Sea and Wadden Sea. Mar Ecol Prog Ser 298:21-39

Wilson WH (1990) Competition and predation in marine softsediment communities. Annu Rev Ecol Syst 21:221-241

Witbaard R, Duineveld GCA (1989) Some aspects of the biology and ecology of the burrowing shrimp Callianassa subterranea (Montagu) (Thalassinidea) from the Southern North-Sea. Sarsia 74:209-219

Woodin SA, Marinelli RL, Lindsay SM (1998) Process-specific cues for recruitment in sedimentary environments: geochemical signals? J Mar Res 56:535-558 
Appendix 1. Analytical analysis of the simple competition model without sediment effect

The simple competition model (Eq. 1) has the following nullclines for Amphiura filiformis $\left(A^{*}\right)$ :

$$
\begin{aligned}
& \frac{\mathrm{d} A}{\mathrm{~d} t}=r_{A} A \frac{F_{0}-a_{A} A-a_{C} C}{F_{0}-a_{A} A-a_{C} C+H_{F, A}}-m_{A} A=0 \\
& \Rightarrow A^{*}=-\frac{a_{C}}{a_{A}} C^{*}+\frac{F_{0}}{a_{A}}-\frac{m_{A} H_{F_{1} A}}{\left(r_{A}-m_{A}\right) a_{A}} \vee A^{*}=0
\end{aligned}
$$

Similarly the nullclines for Callianassa subterranea $\left(C^{*}\right)$ are:

$$
\begin{aligned}
& \frac{\mathrm{d} C}{\mathrm{~d} t}=r_{C} C \frac{F_{0}-a_{A} A-a_{C} C}{F_{0}-a_{A} A-a_{C} C+H_{F, C}}-m_{C} C=0 \\
& \Rightarrow A^{*}=-\frac{a_{C}}{a_{A}} C^{*}+\frac{F_{0}}{a_{A}}-\frac{m_{C} H_{F_{1} C}}{\left(r_{C}-m_{C}\right) a_{A}} \vee C^{*}=0
\end{aligned}
$$

These nullclines are linear with the same slope $\left(-a_{C} / a_{A}\right)$, so there cannot be stable coexistence nor alternative equilibria, as it is then required that both nullclines cross. The equilibrium with only Amphiura filiformis becomes stable if the intercept of the A. filiformis nullcline is larger than the intercept of the Callianassa subterranea nullcline:

$$
\frac{F_{0}}{a_{A}}-\frac{m_{A} H_{F, A}}{\left(r_{A}-m_{A}\right) a_{A}}>\frac{F_{0}}{a_{A}}-\frac{m_{C} H_{F, C}}{\left(r_{C}-m_{C}\right) a_{A}}
$$

Thus:

$$
\frac{m_{A}}{\left(r_{A}-m_{A}\right)} H_{F, A}<\frac{m_{C}}{\left(r_{C}-m_{C}\right)} H_{F, C}
$$

This means that the superior species can deplete the resource more effectively or that it has a smaller ratio between losses and maximum net growth rate.

Editorial responsibility: Howard Browman (Associate Editorin-Chief), Storebø, Norway
Submitted: February 21, 2006; Accepted: June 20, 2006 Proofs received from author(s): January 18, 2007 